\title{
Multidose Container with Airless Pump
}

National Cancer Institute

\section{Source}

National Cancer Institute. Multidose Container with Airless Pump. NCI Thesaurus. Code C149671.

Multidose container with an integ ral pump designed to protect the contents against in use-contamination. 